\title{
Regulation of Expression of Oxacillin-Inducible Methionine Sulfoxide Reductases in Staphylococcus aureus
}

\author{
Kyle R. Baum, ${ }^{1}$ Zulfiqar Ahmad, $^{2}$ and Vineet K. Singh ${ }^{1}$ \\ ${ }^{1}$ Department of Microbiology and Immunology, Kirksville College of Osteopathic Medicine, A.T. Still University of Health Sciences, \\ Kirksville, MO 63501, USA \\ ${ }^{2}$ Department of Biochemistry, Kirksville College of Osteopathic Medicine, A.T. Still University of Health Sciences, \\ Kirksville, MO 63501, USA
}

Correspondence should be addressed to Vineet K. Singh; vsingh@atsu.edu

Received 5 June 2015; Revised 26 August 2015; Accepted 2 September 2015

Academic Editor: Juan F. Martín

Copyright (C) 2015 Kyle R. Baum et al. This is an open access article distributed under the Creative Commons Attribution License, which permits unrestricted use, distribution, and reproduction in any medium, provided the original work is properly cited.

Cell wall-active antibiotics cause induction of a locus that leads to elevated synthesis of two methionine sulfoxide reductases (MsrA1 and $\mathrm{MsrB}$ ) in Staphylococcus aureus. To understand the regulation of this locus, reporter strains were constructed by integrating a DNA fragment consisting of the $m s r A 1 / m s r B$ promoter in front of a promoterless lacZ gene in the chromosome of wild-type and MsrA1-, MsrB-, MsrA1/MsrB-, and SigB-deficient methicillin-sensitive S. aureus strain SH1000 and methicillin-resistant S. aureus strain COL. These reporter strains were cultured in TSB and the cellular levels of $\beta$-galactosidase activity in these cultures were assayed during different growth phases. $\beta$-galactosidase activity assays demonstrated that the lack of MsrA1, MsrB, and SigB upregulated the $m s r A 1 / m s r B$ promoter in $S$. aureus strain SH1000. In $S$. aureus strain COL, the highest level of $\beta$-galactosidase activity was observed under the conditions when both MsrAl and MsrB proteins were absent. The data suggest that the $m s r A 1 / m s r B$ locus, in part, is negatively regulated by MsrA1, MsrB, and SigB in S. aureus.

\section{Introduction}

Staphylococcus aureus is part of the microbiome of roughly $30 \%$ of people who show no clinical symptoms [1]. It is an opportunistic human pathogen that can cause a wide variety of diseases and can involve any organ system in the human body. Diseases caused by $S$. aureus may include mild skin infections such as folliculitis and impetigo to fatal conditions such as pneumonia, osteomyelitis, and endocarditis [2]. Treatment of $S$. aureus infections has become problematic as it has developed numerous mechanisms to become resistant to almost all known antibiotics [3, 4].

It was previously reported that exposure of $S$. aureus to oxacillin and other cell wall-active antibiotics increases the expression of $m s r A 1$ and $m s r B$ both at the transcriptional and at the protein level $[5,6]$. Pathogenic bacterial species are exposed to a variety of extremely potent reactive oxygen species (ROS) by the host phagocytic cells during the course of phagocytosis that are damaging to all cellular macromolecules. ROS can cause damage to proteins by the oxidation of sulfhydryl groups, reduction of disulfides, oxidative adduction of amino acid residues close to metalbinding sites, and peptide fragmentation [7]. In particular, ROS oxidize the sulfur atom of protein-bound methionine residues resulting in methionine sulfoxide $(\mathrm{Met} \mathrm{O})$ and loss of protein function. However, almost all biological species possess the ability to reduce oxidized methionines [8]. MsrA and MsrB proteins reduce S- and R-epimers of methionine sulfoxides (MetO), respectively [8].

In S. aureus, genes encoding MsrAl and MsrB are the first and second genes of a four-gene cluster that are cotranscribed [6]. A mutation in the $m s r A l$ gene increased the susceptibility of $S$. aureus to oxidative stress $[6,9]$. More recently, it was shown that the MsrAl protein was critical for $S$. aureus in establishing an infection in mice [10]. Interestingly, the MsrA1-deficient $S$. aureus was shown to possess an elevated level of MsrB [9] giving rise to the speculation of autoregulation of the $m s r A 1 / m s r B$ locus. Additionally, sigma factor $\mathrm{B}$ (SigB) is an alternative sigma factor that is involved in regulating the expression of stress response genes in S. aureus [11]. 
TABLE 1: Bacterial strains used in this study.

\begin{tabular}{|c|c|c|}
\hline Strains & Characteristics & Reference \\
\hline SH1000 & S. aureus strain $8325-4$ with functional RsbU & [11] \\
\hline $\mathrm{COL}$ & Homogeneous in methicillin-resistance expression & [37] \\
\hline $\mathrm{SH} 1000 \Delta m s r A 1$ & msrA1 mutant of SH1000 & [10] \\
\hline $\mathrm{SH} 1000 \Delta m s r B$ & $m s r B$ mutant of SH1000 & [10] \\
\hline $\mathrm{SH} 1000 \Delta m s r A 1-m s r B$ & $m s r A 1-m s r B$ double mutant of SH1000 & [10] \\
\hline $\mathrm{SH} 1000 \Delta \operatorname{sig} B$ & sigB mutant of SH1000 & [14] \\
\hline $\mathrm{COL} \Delta m s r A 1$ & msrA1 mutant of SH1000 & {$[6]$} \\
\hline COL $\Delta m s r B$ & $m s r B$ mutant of SH1000 & This study \\
\hline COL $\Delta m s r A 1-m s r B$ & $m s r A 1-m s r B$ double mutant of SH1000 & This study \\
\hline COL $\Delta s i g B$ & sigB mutant of SH1000 & {$[38]$} \\
\hline SH1000-(A1/B)P-lacZ & $m s r A 1 / m s r B$ promoter-lacZ fusion in SH1000 $\left(\mathrm{Erm}^{R}\right)$ & [13] \\
\hline $\mathrm{SH} 1000 \Delta m s r A 1-(\mathrm{A} 1 / \mathrm{B}) \mathrm{P}-\mathrm{lac} Z$ & $m s r A 1 / m s r B$ promoter-lacZ fusion in $m s r A 1$ mutant of $\mathrm{SH} 1000\left(\operatorname{Kan}^{R}, \operatorname{Erm}^{R}\right)$ & This study \\
\hline $\mathrm{SH} 1000 \Delta m s r B-(\mathrm{A} 1 / \mathrm{B}) \mathrm{P}-\mathrm{lac} Z$ & $m s r A 1 / m s r B$ promoter-lacZ fusion in $m s r B$ mutant of $\mathrm{SH} 1000\left(\mathrm{Kan}^{R}, \mathrm{Erm}^{R}\right)$ & This study \\
\hline $\mathrm{SH} 1000 \Delta m s r A 1-m s r B-(\mathrm{A} 1 / \mathrm{B}) \mathrm{P}-\mathrm{lac} Z$ & $m s r A 1 / m s r B$ promoter-lacZ fusion in $m s r 1-m s r B$ mutant of $S H 1000\left(\operatorname{Kan}^{R}, \operatorname{Erm}^{R}\right)$ & This study \\
\hline $\mathrm{SH} 1000 \Delta \operatorname{sig} B-(\mathrm{A} 1 / \mathrm{B}) \mathrm{P}-\mathrm{lac} Z$ & $m s r A 1 / m s r B$ promoter-lacZ fusion in sigB mutant of $\mathrm{SH} 1000\left(\mathrm{Kan}^{R}, \mathrm{Erm}^{R}\right)$ & This study \\
\hline COL-(A1/B)P-lacZ & $m s r A 1 / m s r B$ promoter-lac $Z$ fusion in COL $\left(\mathrm{Erm}^{R}\right)$ & This study \\
\hline COL $\Delta m s r A 1-(\mathrm{A} 1 / \mathrm{B}) \mathrm{P}-\mathrm{lac} Z$ & $m s r A 1 / m s r B$ promoter-lacZ fusion in $m s r A 1$ mutant of COL $\left(\operatorname{Kan}^{R}, \operatorname{Erm}^{R}\right)$ & This study \\
\hline $\mathrm{COL} \Delta m s r B-(\mathrm{A} 1 / \mathrm{B}) \mathrm{P}-\mathrm{lac} Z$ & $m s r A 1 / m s r B$ promoter-lacZ fusion in $m s r B$ mutant of COL $\left(\operatorname{Kan}^{R}, \mathrm{Erm}^{R}\right)$ & This study \\
\hline $\mathrm{COL} \Delta m s r A 1-m s r B-(\mathrm{A} 1 / \mathrm{B}) \mathrm{P}-l a c Z$ & $m s r A 1 / m s r B$ promoter-lacZ fusion in $m s r A 1-m s r B$ mutant of COL $\left(\operatorname{Kan}^{R}, \mathrm{Erm}^{R}\right)$ & This study \\
\hline $\mathrm{COL} \Delta \operatorname{sig} B-(\mathrm{A} 1 / \mathrm{B}) \mathrm{P}-\mathrm{lac} Z$ & $m s r A 1 / m s r B$ promoter-lacZ fusion in sigB mutant of COL $\left(\operatorname{Kan}^{R}, \operatorname{Erm}^{R}\right)$ & This study \\
\hline
\end{tabular}

Thus, it seems plausible that SigB may have a role in the regulation of the $m s r A 1 / m s r B$ locus. Findings of this study provide evidence that the $m s r A 1 / m s r B$ locus is negatively regulated by the products of this locus and SigB.

\section{Materials and Methods}

2.1. Bacterial Strains, Antibiotics, and Growth Conditions. The bacterial strains used in this study are shown in Table 1. S. aureus cultures were grown aerobically at $37^{\circ} \mathrm{C}$ in tryptic soy broth (TSB) in a shaking incubator $(220 \mathrm{rpm})$ or on tryptic soy agar (TSA) by incubation for 24-48 h. Overnight cultures of $S$. aureus reporter strains were prepared in the presence of erythromycin at $10 \mu \mathrm{g} \mathrm{mL}^{-1}$. Oligonucleotide primers used in this study were obtained from Eurofins and are shown in Table 2.

2.2. Transduction of $m s r A 1 / m s r B$ Promoter-lacZ into $S$. aureus Strains. Construction of $m s r A 1 / m s r B$ promoter-lac $Z$ reporter strain has been previously described [6]. In this construct, a $1.3 \mathrm{~kb}$ DNA fragment starting 44 nucleotides downstream and going upstream of the $m s r A 1$ gene cloned in front of a promoterless lacZ gene in the vector pAZ106 [12] was integrated in the chromosome of $S$. aureus strain RN450 $[5,6]$. The $m s r A 1 / m s r B$ promoter-lac $Z$ reporter was transduced into various strains of $S$. aureus using a phage $80 \alpha$ transduction procedure. Strains used in this study were verified by PCR.
TABLE 2: Oligonucleotide primers used in this study.

\begin{tabular}{ll}
\hline Oligo & Sequence $\left(5^{\prime} \rightarrow 3^{\prime}\right)$ \\
\hline P1 & GCTAACGTCATTGAATATG \\
P2 & GGAAGTAACCTCTGGATCA \\
P3 & GTTACACAAGAAAACGGCA \\
P4 & TCATCATCGTGTTTTGGG \\
P5 & AGGATGTTTCTGGTGCATGG \\
P6 & GACACAACTTCTCCTTCAGT \\
P7 & CCTTTGAACGGAAGTTTGA \\
P8 & TCTAATAGCAACCCACCT \\
P9 & GCTAACGTCATTGAATATG \\
P10 & GGATGGTTCGGATAATGC \\
P11 & GATTGGGATCATAGCGTCA \\
P12 & CTTCAGAGTTAATGGGACCA \\
P13 & AGGCATCAAGTCAGTCGTATC \\
P14 & GAAGTAACCTCTGGATCAAACG \\
P15 & GGTATGGTAAGAACTGAAGTGC \\
P16 & ATTGCAGCGGAATTGATACAG \\
P17 & TCTCCAATTGCAGGACGTGT \\
P18 & ACACTTCAAATCCTTCACCGTCT \\
P19 & TCCACAAGTCGCACGTACAG \\
P20 & GGAAGGCTTGCTACATCTAACG \\
\hline
\end{tabular}

2.3. Determination of the $m s r A 1 / m s r B$ Promoter Strength in S. aureus. To determine if the $m s r A 1 / m s r B$ locus is autoregulated, the expression of lac $Z$ from the $m s r A 1 / m s r B$ promoterlacZ fusion was investigated in MsrA1-, MsrB-, and MsrA1MsrB-deficient strains of S. aureus strains SH1000 and COL. 
In addition, SigB is a major regulator of stress response in $S$. aureus. Therefore, the strength of the $m s r A 1 / m s r B$ promoter was also assessed in a sigB mutant. Overnight cultures of these strains were diluted $(1: 100)$ and grown at $37^{\circ} \mathrm{C}$ with shaking. These cultures were grown to $\mathrm{OD}_{600}=0.5$ that was considered time 0 and the levels of $\beta$-galactosidase activity in these cultures were measured at different time points $(0,90$, 180,270 , and $360 \mathrm{~min}$ ) as an indicator of the strength of the $m s r A 1 / m s r B$ promoter.

\subsection{Expression of $m s r A 1 / m s r B$ Promoter in the Presence of a} Cell Wall-Active Antibiotic, Oxacillin. Previous studies [5, 6, $9,10,13$ ] have shown that, in the presence of oxacillin, there is an increased production of MsrA1 and MsrB in S. aureus. To further investigate the regulation of the $m s r A 1 / m s r B$ locus and to see if it can be magnified in the presence of oxacillin, overnight cultures of wild-type and the derivative msrA1$m s r B$ mutant of $S$. aureus strain COL were diluted $(1: 100)$ in fresh TSB and grown to $\mathrm{OD}_{600}$ of $0.5 .10 .0 \mathrm{~mL}$ of the culture was split into two $15 \mathrm{~mL}$ tubes. To one of the cultures, oxacillin was added to the final concentration of $1.0 \mathrm{mg} \mathrm{mL}^{-1}$. Both cultures with and without oxacillin were allowed to grow for an additional $2 \mathrm{~h}$ at $37^{\circ} \mathrm{C}$ with shaking. Bacterial cells were harvested by centrifugation and $\beta$-galactosidase activities in these cells were measured.

2.5. Measurement of $\beta$-Galactosidase Activity. The $\mathrm{OD}_{600}$ of the culture was determined as a measure of cell density and cells were subsequently collected by centrifugation. For precise optical density readings, cultures were diluted appropriately to bring density into measurable range. The cell pellet was used to measure $\beta$-galactosidase activity as described previously using O-nitrophenyl- $\beta$-D-galactopyranoside (ONPG) as the substrate $[5,6,13]$.

2.6. Quantitative Real-Time PCR ( $q R T-P C R$ ) Assays. qRTPCR assays were used to verify induced expression of the genes of the $m s r A 1 / m s r B$ locus under oxacillin stress and to validate the lac $Z$ reporter expression data in $\operatorname{sig} B$ mutants. Cultures of $S$. aureus strain COL were grown to $\mathrm{OD}_{600}=$ 0.3 and divided into two tubes. One tube was stressed with oxacillin at a concentration of $1.0 \mathrm{mg} \mathrm{mL}^{-1}$ for $2 \mathrm{~h}$. Total RNA was extracted from these oxacillin stressed and control cultures as described previously [14]. For the validation of lac $Z$ data, the wild-type and $s i g B$ mutant strains of $S$. aureus were allowed to grow for $90 \mathrm{~min}$ and $6 \mathrm{~h}$ after reaching the $\mathrm{OD}_{600}=0.5$ and total RNA from these cultures were extracted. cDNA from DNase treated $0.5 \mu \mathrm{g}$ of total RNA was synthesized in a $20 \mu \mathrm{L}$ reverse transcription reaction containing random hexamers and SuperScript III reverse transcriptase (Invitrogen). All real-time PCR reactions were carried out with Bio-Rad iCycler (iQ5 system). The transcript level of $m s r A 1$ was quantified using primers P13 and P14, that of $m s r B$ was quantified using P15 and P16, and that of the gene encoding the IIa(PTS) was quantified using primers P17 and P18. Transcript levels of genes were normalized to DNA gyrase mRNA using primers P19 and P20 based on a previous report $[15,16]$. Changes in gene expression were calculated using the formula $2^{-\Delta \Delta \mathrm{Cq}}$ as described [17].

2.7. Statistical Analysis. All results are reported as the mean \pm SE of at least three independent experiments. Data were analyzed with Student's $t$-test using R Studio for Windows (version $0.98 .1103,3.1 .3$ ). Statistical significance was set at $p \leq$ 0.05 .

\section{Results}

3.1. Construction of $m s r A 1 / m s r B$ Promoter-lacZ Reporter in Wild-Type and msrA1, msrB, msrA1-msrB, and sigB Mutants of $S$. aureus. Previously created $m s r A 1, m s r B$, $m s r A 1-m s r B$, and $\operatorname{sig} B$ knockout mutants of $S$. aureus strain SH1000 [6, 9,10 ] were transduced in the methicillin-resistant $S$. aureus strain COL. These mutants and the presence of mecA gene in these strains were verified by PCR (see Supplemental Figures S1-S2 in Supplementary Material available online at http://dx.doi.org/10.1155/2015/617925). The $m s r A 1 / m s r B$ promoter-lac $Z$ fusion was subsequently integrated into the chromosome of these mutant strains using a bacteriophage transduction procedure. Overall, five $m s r A 1 / m s r B$ promoterlac $Z$ reporter strains were created in methicillin-resistant as well as methicillin-sensitive $S$. aureus backgrounds. Proper integration of the $m s r A 1 / m s r B$ promoter-lac $Z$ fusion was also confirmed by PCR (Supplemental Figure S3).

3.2. Regulation of $m s r A 1 / m s r B$ Locus in S. aureus. Previously, we reported higher MsrB levels in MsrA1-deficient $S$. aureus cells $[9,10]$. This led to the speculation that the $m s r A 1 / m s r B$ locus may in part be regulated by the products of this locus. To investigate this possibility, the level of $\beta$-galactosidase was measured in MsrA1-, MsrB-, and MsrA1-MsrB-deficient strains of $S$. aureus. $\beta$-galactosidase activity levels were higher in these strains compared to the activity level in the wildtype $S$. aureus strain SH1000 (Figure 1). The $m s r A 1 / m s r B$ promoter-lac $Z$ reporter was also studied in the methicillinresistant strain COL. Overall, the expression of lac $Z$ was lower in methicillin-resistant $S$. aureus compared to the methicillinsensitive $S$. aureus (Figures 1(b) and 2(b)). In addition, $\beta$-galactosidase activity comparison revealed that only the msrA1-msrB double mutant strains had higher activity levels compared to the wild-type COL at the various time points (Figure 2(b)). In the individual $m s r A 1$ or $m s r B$ mutant strains, a significant increase in $\beta$-galactosidase activity was not observed compared to wild-type S. aureus COL (Figure 2(b)).

3.3. Role of SigB in the Regulation of $m s r A 1 / m s r B$ Locus in $S$. aureus. Measurement of $\beta$-galactosidase activity demonstrated that there was increased expression of lac $Z$ from the $m s r A 1 / m s r B$ promoter when $S$. aureus was deficient of SigB in strain SH1000 (Figure 3(b)). However, in S. aureus COL, no such increase in the expression of lac $Z$ was observed from the $m s r A 1 / m s r B$ promoter under SigB-deficient conditions compared to the wild-type strain (Figure 4(b)). In qRT-PCR assays, a relatively higher level of $m s r A 1$ transcripts was observed in sigB mutant of S. aureus strain SH1000 compared 


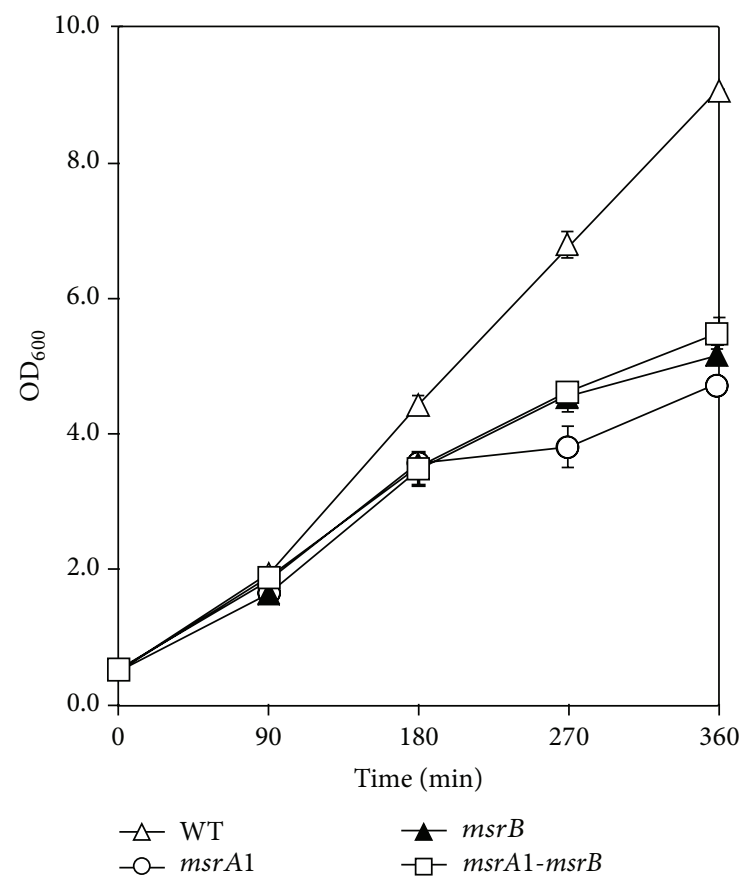

(a)

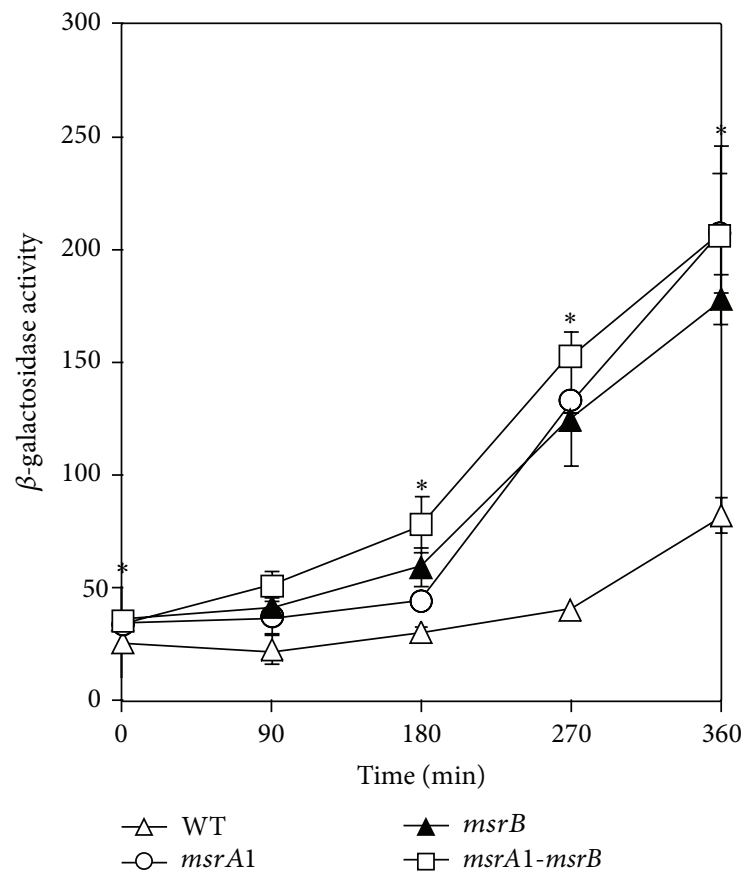

(b)

FIGURE 1: Regulation of $m s r A 1 / m s r B$ locus in a methicillin-sensitive S. aureus strain SH1000. The $m s r A 1 / m s r B$ promoter-lacZ reporter strains were cultured in TSB and growth was measured as $\mathrm{OD}_{600}$ (a). $\beta$-galactosidase activity levels were measured in wild-type $S$. aureus strain SH1000 (open triangles) and its derivatives $m s r A 1$ (open circles), $m s r B$ (closed triangles), and $m s r A 1-m s r B$ (open square) mutants during different stages of growth (b). Values indicate averages of data from at least three independent experiments \pm standard error (SE) (* significant at $p \leq 0.05)$.

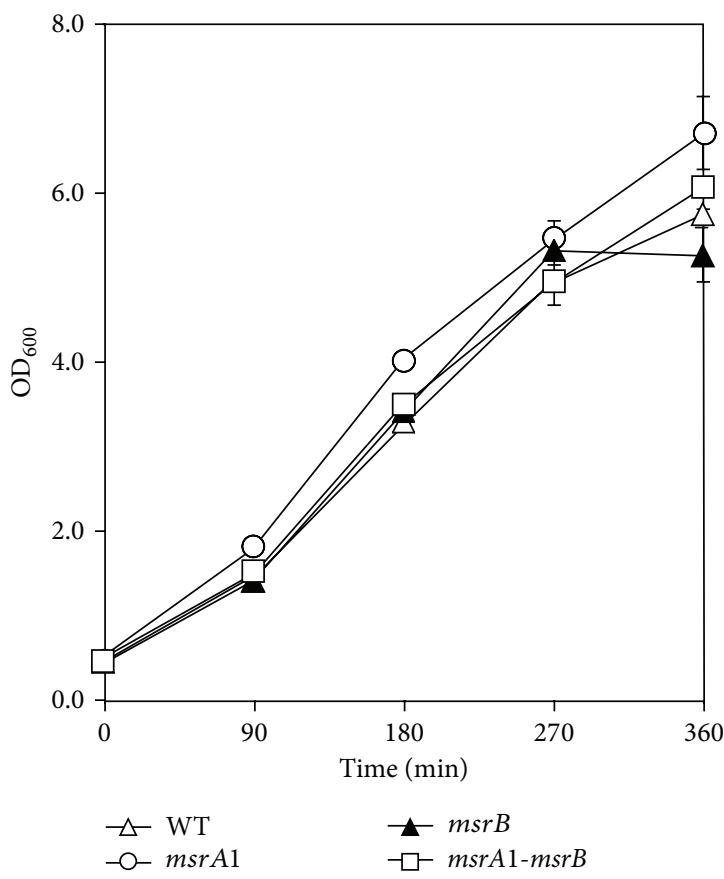

(a)

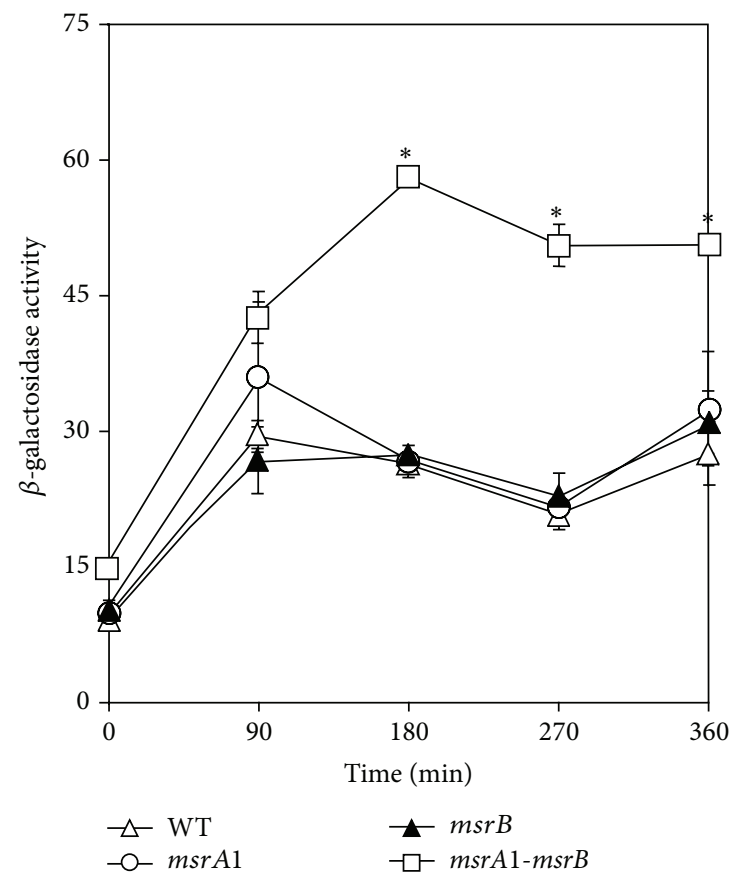

(b)

FIgURE 2: Regulation of $m s r A 1 / m s r B$ locus in a methicillin-resistant $S$. aureus strain COL. The $m s r A 1 / m s r B$ promoter-lacZ reporter strains were cultured in TSB and growth was measured as $\mathrm{OD}_{600}$ (a). $\beta$-galactosidase activity levels were measured in wild-type $S$. aureus strain $\mathrm{COL}$ (open triangles) and its derivatives $m s r A 1$ (open circles), $m s r B$ (closed triangles), and $m s r A 1$ - $m s r B$ (open square) mutants during different stages of growth (b). Values indicate averages of data from at least three independent experiments \pm standard error $(*$ significant at $p \leq 0.05)$. 


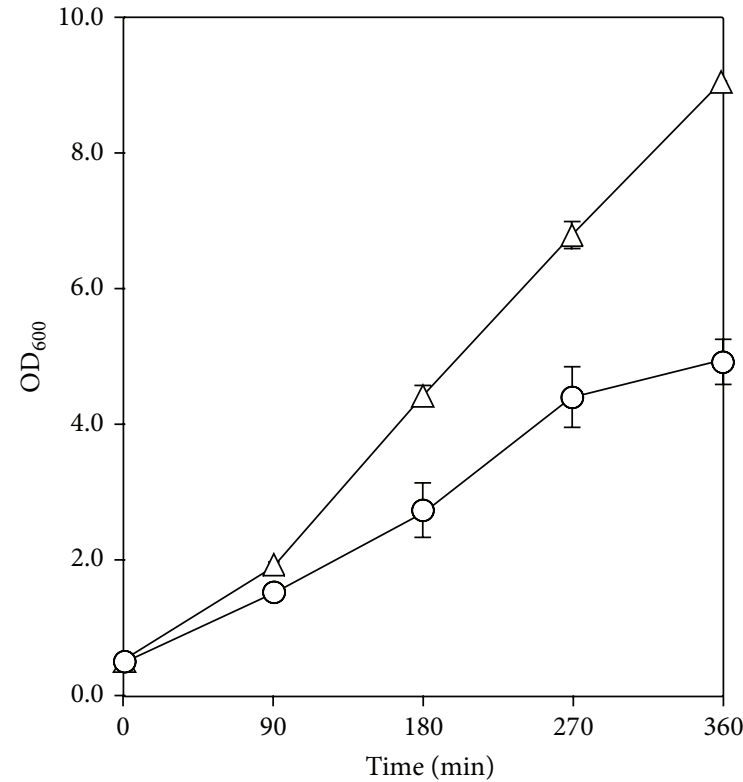

$-\triangle$ WT

$-\mathrm{O}-\operatorname{sig} B$

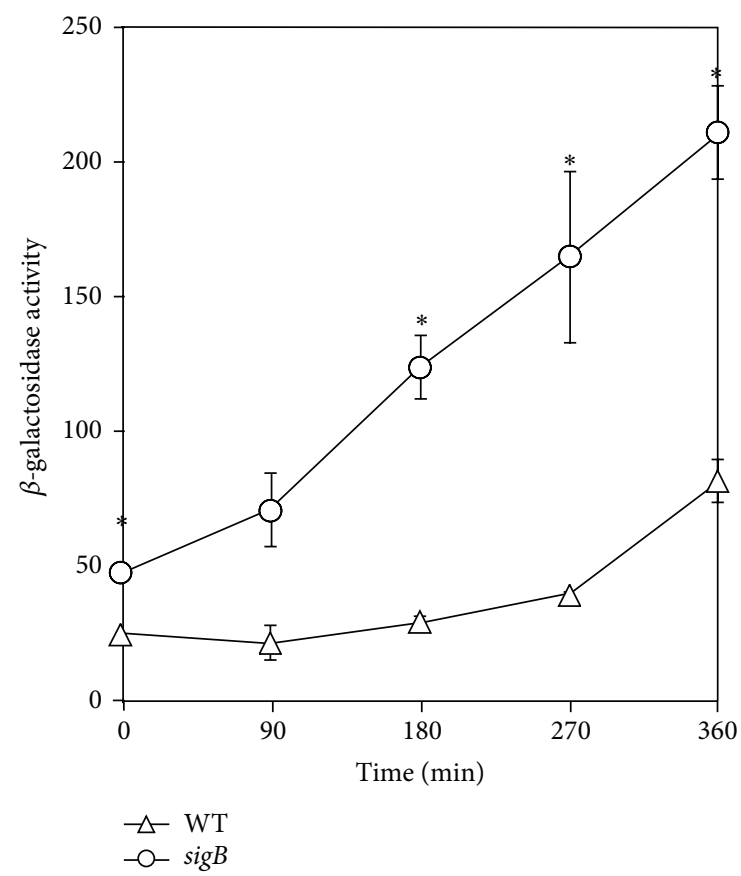

(b)

(a)

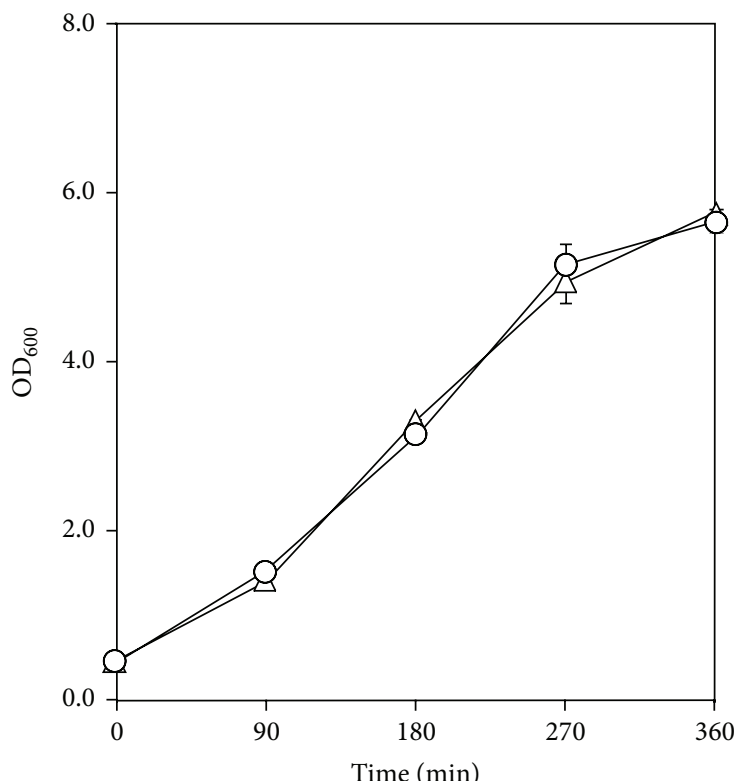

$\triangle-\mathrm{WT}$

-O- sigB

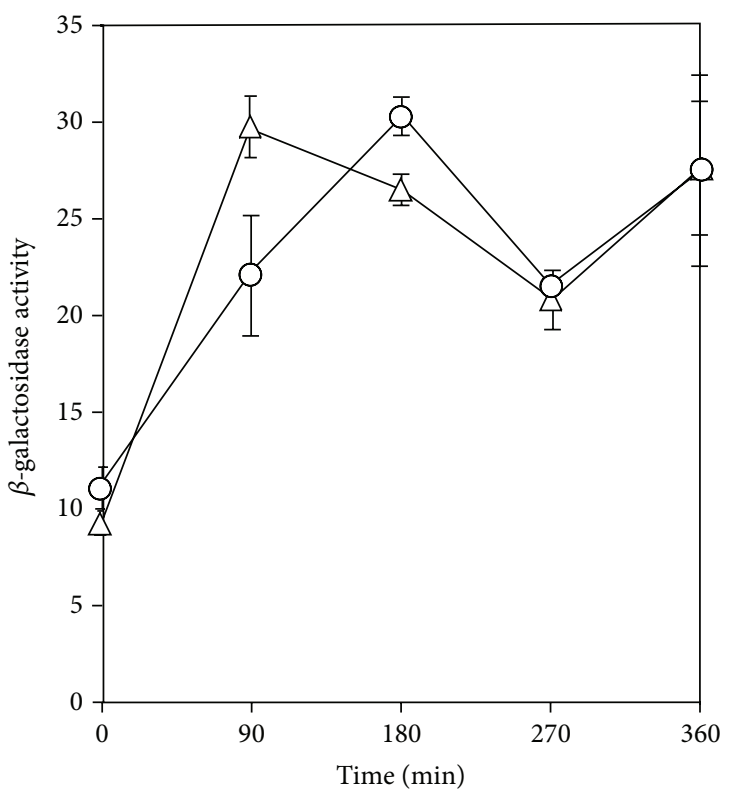

$\triangle-$ WT

$-O-\operatorname{sig} B$

(a)

(b)

Figure 4: Regulation of $m s r A 1 / m s r B$ locus in a methicillin-resistant $S$. aureus strain COL by SigB. The $m s r A 1 / m s r B$ promoter-lacZ reporter strains were cultured in TSB and growth was measured as $\mathrm{OD}_{600}$ (a). $\beta$-galactosidase activity levels were measured in $S$. aureus strain COL (open triangles) and its derivative $\operatorname{sig} B$ mutant (closed squares) during different stages of growth (b). Values indicate averages of data from at least three independent experiments \pm standard error ( $*$ significant at $p \leq 0.05)$. 
TABLE 3: Expression levels of $m s r A 1$ in sigB mutants relative to wildtype $S$. aureus strains SH1000 and COL.

\begin{tabular}{lcc}
\hline \multirow{2}{*}{ Strain } & \multicolumn{2}{c}{ Fold increase in expression } \\
& $90 \mathrm{~min}$ & $6 \mathrm{~h}$ \\
\hline SH1000 $\Delta$ sigB1.30 & 3.16 & \\
COL $\Delta$ sigB & 0.98 & 1.52 \\
\hline
\end{tabular}

Values indicate averages of three independent experiments.

TABLE 4: Induced expression of $m s r A 1 / m s r B$ locus genes in S. aureus strain COL under oxacillin stress.

\begin{tabular}{lc}
\hline Gene & Fold increase in expression under oxacillin stress \\
\hline$m s r A 1$ & 22.9 \\
$m s r B$ & 18.97 \\
$I I a(P T S)$ & 13.45
\end{tabular}

Values indicate averages of three independent experiments.

to the wild-type strain (Table 3). However, this increase in $m s r A 1$ gene expression was not evident in the sigB mutant of $S$. aureus strain COL (Table 3) supporting the findings of the $m s r A 1 / m s r B$ promoter-lac $Z$ data in sigB mutant strains.

3.4. Induction of $m s r A 1 / m s r B$ Locus in the Presence of Cell Wall-Active Antibiotic, Oxacillin. Previous studies have shown that the $m s r A 1 / m s r B$ locus is induced by the cell wallactive antibiotics, oxacillin, vancomycin, and D-cycloserine, in a methicillin-sensitive $S$. aureus strain [5]. In a later study, while the $m s r A 1 / m s r B$ locus remained inducible in the presence of $\mathrm{D}$-cycloserine and vancomycin, no induction of this locus was noted in the presence of oxacillin, when similar experiments were carried out in a methicillin-resistant $S$. aureus strain COL [18]. However, in our experiments, a significantly increased $\beta$-galactosidase activity clearly indicates a significant induction of $m s r A 1 / m s r B$ locus in the presence of oxacillin, even in a methicillin-resistant $S$. aureus (Figure 5). We also investigated the expression of the downstream genes of $m s r A 1$ locus in qRT-PCR assays. We determined that the oxacillin stress dramatically induced the expression of $m s r A 1, m s r B$, and the gene encoding IIa(PTS) (Table 4 ). The expression level of the fourth gene of this locus was not investigated due to its very small size. This finding further supports our previous observation of cotranscription of the four genes of the $m s r A 1 / m s r B$ locus $[5,6]$.

3.5. Expression of $m s r A 1 / m s r B$ Locus in MsrA1-MsrB-Deficient $S$. aureus Strain COL in the Presence of Oxacillin. While studying the regulation of the $m s r A 1 / m s r B$ locus in a methicillin-resistant $S$. aureus strain COL, oxacillin was added during the growth of the $m s r A 1 / m s r B$ promoter-lac $Z$ reporter to investigate any magnification of the regulation. In these studies, while an increased lac $Z$ expression was observed in wild-type $S$. aureus strain COL after oxacillin treatment, a more dramatic increase in the lac $Z$ expression in response to oxacillin was seen in MsrA1-MsrB-deficient COL (Figure 6).

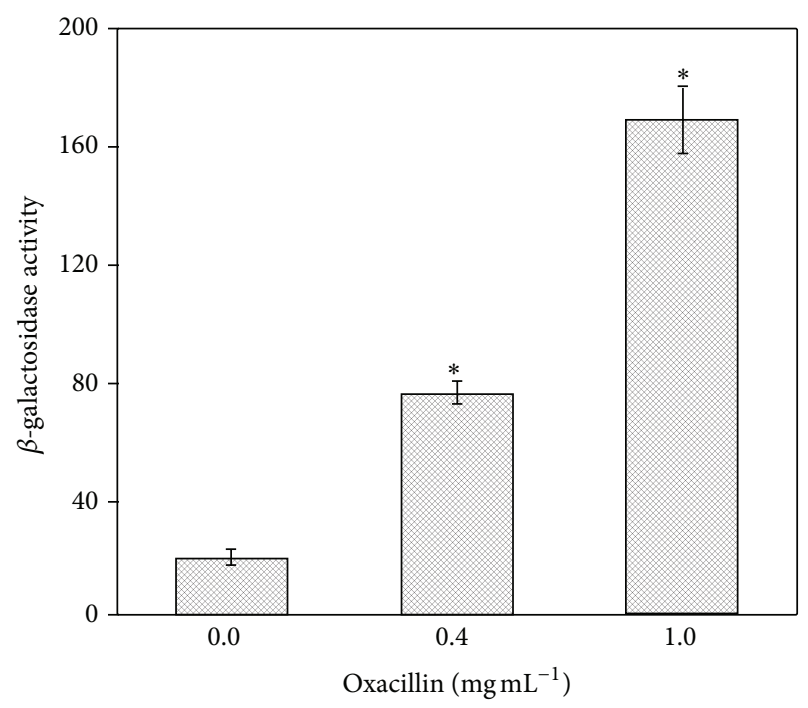

Figure 5: Analysis of $m s r A 1 / m s r B$ promoter-lacZ fusion in S. aureus $\mathrm{COL}$ in response to oxacillin. Bacterial culture was grown in TSB to $\mathrm{OD}_{600}=0.3$ and then exposed to oxacillin $\left(0.4\right.$ and $1.0 \mathrm{mg} \mathrm{mL}^{-1}$, resp.) for $2 \mathrm{~h}$. Subsequently, cells were collected via centrifugation and the $\beta$-galactosidase activity was determined. Values indicate averages of data from at least three independent experiments \pm standard error ( $*$ significant at $p \leq 0.05)$.

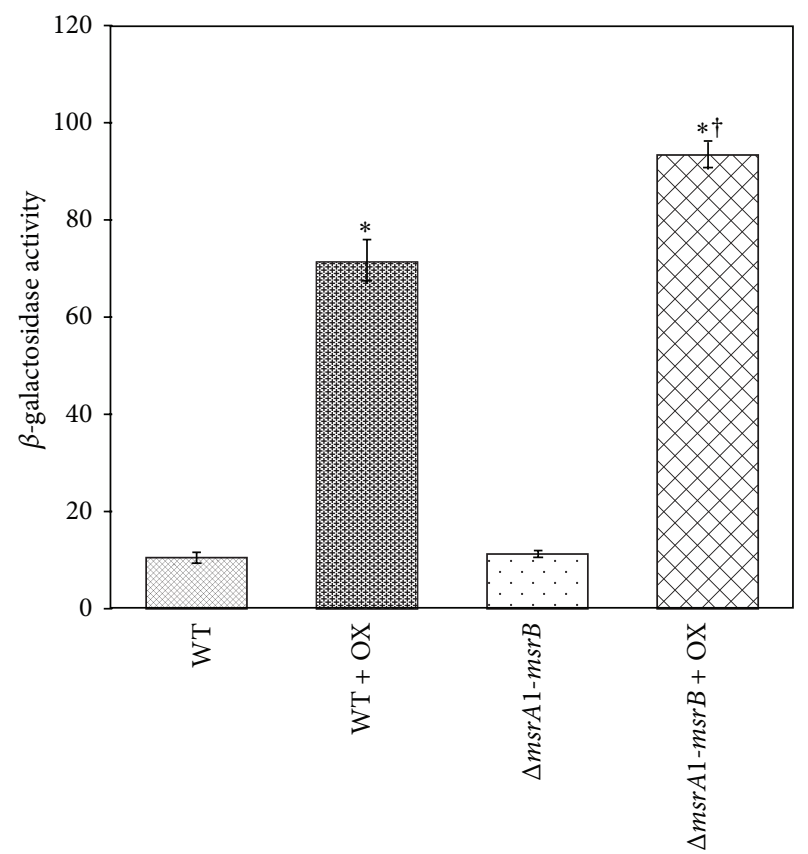

FIgURE 6: Analysis of $m s r A 1 / m s r B$ promoter-lac $Z$ fusion in wildtype and $m s r A 1-m s r B$ double mutant of $S$. aureus $C O L$ in response to oxacillin. At $\mathrm{OD}_{600}=0.5$, cells were treated with oxacillin for $2 \mathrm{~h}$ and the $\beta$-galactosidase activity levels were measured. Values indicate averages of data from at least three independent experiments \pm standard error $(*$ significant between samples with and without oxacillin at $p \leq 0.05$; $\dagger$ significant between oxacillin treated wildtype and the oxacillin treated $m s r A 1-m s r B$ double mutant at $p \leq$ $0.05)$. 


\section{Discussion}

Cell wall-active antibiotics have been used extensively for the treatment of infections caused by bacterial pathogens. $S$. aureus is a major human pathogen and is resistant to most commonly available antibiotics. Interestingly, cell wall-active antibiotics cause induction of a locus in S. aureus that leads to elevated synthesis of two methionine sulfoxide reductases (MsrAl and MsrB) $[5,6]$. These enzymes reduce methionine sulfoxide and play important roles in maintaining protein integrity and function particularly under oxidative stress. These two proteins have also been shown to have roles in the virulence of bacterial pathogens [19-23]. Msr-deficient bacterial mutants show a reduction in the ability to adhere to eukaryotic cells and are thus less likely to establish an inflection $[21,22,24,25]$. It is speculated that the lack of the Msr enzymes compromises the integrity of the bacterial surface proteins responsible for adherence to eukaryotic cells. Reduced Msr activity decreases bacterial survival inside the phagocytic cells [20]. In addition to increased levels of MsrAl and MsrB specifically in response to cell wall-active antibiotics, these proteins in $S$. aureus have been shown to play roles in the survival of bacterial cells under oxidative stress as well as in mice $[6,10]$.

We previously demonstrated that when the msrAl gene is deleted in S. aureus, there is an increase in MsrB synthesis suggesting a possible role in the regulation of this locus [9]. Findings of this study suggest that, in a methicillinsensitive S. aureus strain SH1000, MsrA1 and MsrB individually can downregulate the $m s r A 1 / m s r B$ locus. However, in methicillin-resistant $S$. aureus strain COL, MsrA1 and MsrB both are needed to downregulate the expression of the $m s r A 1 / m s r B$ locus. It is speculated that the $m s r A 1 / m s r B$ locus, to some extent, is differentially regulated between methicillin-resistant and methicillin-sensitive $S$. aureus strains. It is not uncommon to observe a differential gene expression pattern between different $S$. aureus strains. It has been demonstrated that the growth of methicillinresistant $S$. aureus is slower than that of methicillin-sensitive $S$. aureus in the lag phase but not during the exponential phase and that the alterations in virulence between these two strains may at least partially be due to the growth rate differences [26]. Deletion of a gene encoding nitric oxide synthase (NOS) in a methicillin-resistant $S$. aureus reduced virulence as seen by decreased bacterial survival and smaller abscess formation [27]. However, NOS was shown to have a limited role in a methicillin-sensitive $S$. aureus [28]. Expression of genes encoding staphylococcal superantigenlike (SSL) proteins also varies between $S$. aureus strains $[29,30]$. Significant differences were also noted between the protein profiles of the methicillin-resistant and methicillinsensitive S. aureus strains exposed to Triton X-100 [31].

It is well established that the $m s r A 1 / m s r B$ locus is selectively induced in the presence of cell wall-active antibiotics [5]. These antibiotics interfere with the bacterial cell wall synthesis and, as a result, the cells become fragile and susceptible to lysis. Expression of $m s r A 1 / m s r B$ locus is not induced by antibiotics that target other bacterial metabolic pathways [5]. In a previous report, it was shown that the $m s r A 1 / m s r B$ locus was not induced by the presence of oxacillin but was induced by the presence of D-cycloserine and vancomycin in a methicillin-resistant $S$. aureus [18]. However, data from our study provide clear evidence that oxacillin does in fact induce the $m s r A 1 / m s r B$ locus in a methicillin-resistant background of $S$. aureus. The previous report [18] did not observe any induction because the bacterialcells were not exposed to a high enough concentration to impose antibiotic stress in a methicillin-resistant $S$. aureus strain. Furthermore, we explored the induction of $m s r A l / m s r B$ genes in $m s r A 1$ $m s r B$ double mutant in methicillin-resistant strain COL. An increase in induction of the $m s r A 1 / m s r B$ locus was further magnified in $m s r A 1-m s r B$ double mutant exposed to oxacillin compared to the wild-type $S$. aureus COL in response to oxacillin. This further confirms the notion of downregulation of the $m s r A 1 / m s r B$ locus by MsrAl and MsrB and this is more likely an indirect effect. This speculation of an indirect regulation is based on the fact that, after conducting a protein domain search (http://prosite.expasy.org/), no specific DNAbinding domain was observed in MsrAl and MsrB proteins. It is possible that the MsrAl and MsrB enzymes are critical in maintaining the integrity of a cytoplasmic transcriptional regulator that is involved in the regulation of expression of this locus.

In recent years, regulation of $m s r A$ and $m s r B$ has been studied extensively across multiple species; however, none have shown that MsrA or MsrB directly or indirectly regulates its own expression. It has been demonstrated that RynB regulates the synthesis of Escherichia coli MsrB but not MsrA by binding to the $5^{\prime}$ untranslated region of $m s r B$ mRNA and interfering with its binding to the ribosome [32]. Nitric oxide, which is induced in Ulva fasciata upon exposure to light, upregulates the expression of $m s r$ genes in the intertidal macroalga [33]. In Saccharomyces cerevisiae, calcium phospholipid binding protein (CPBP) interacts with the $m s r A$ promoter and enhances its expression [34]. In Bacillus subtilis, a transcriptional regulator, Spx, is shown to significantly upregulate the expression of $m s r A$ and $m s r B$ [35]. Spx also upregulates $m s r A 1$ expression in $S$. aureus. Teicoplanin induces $m s r A 1 / m s r B$ expression in $S$. aureus. However, in $S$. aureus spx mutant, teicoplanin exposure resulted in no significant induction of this locus, whereas, in the $s p x$ mutant strain complemented with the wild-type $s p x$ gene, $m s r A 1 / m s r B$ induction in response to teicoplanin exposure was restored [36]. Additionally, in the spx mutant, basal $m s r A 1$ mRNA was significantly lower than spx complemented strain [36].

SigB is the alternative sigma factor in S. aureus that plays a role in the regulation of expression of stress responsive genes in S. aureus [11]. In addition, SigB is also associated with the regulation of expression of the virulence genes in S. aureus [11]. In a previous report, the level of expression of $m s r A 1 / m s r B$ locus was investigated between RN450 ( $\mathrm{SigB}^{-}$) and $\mathrm{SH} 1000\left(\mathrm{SigB}^{+}\right)[18]$. It was shown that, in S. aureus strain SH1000, $m s r A 1 / m s r B$ expression was $30 \%$ more induced than in S. aureus strain RN450 in the presence of oxacillin [18]. In contrast, our study shows that $\operatorname{SigB}$ in fact downregulates the expression of $m s r A 1 / m s r B$ locus in $S$. aureus in the methicillin-sensitive $S$. aureus strain SH1000 and plays no 
role in the regulation of this locus in methicillin-resistant strain COL.

In summary, this study provides evidence that the expression of the $m s r A 1 / m s r B$ locus is enhanced when $S$. aureus is deficient in MsrA1, MsrB, or both in a methicillin-sensitive $S$. aureus. However, in methicillin-resistant $S$. aureus, increased expression of the $m s r A 1 / m s r B$ locus was apparent only when the bacterial cells were deficient in both MsrAl and MsrB. In addition, $\mathrm{SigB}$ also in part downregulates the expression of this locus in methicillin-sensitive $S$. aureus but not in methicillin-resistant S. aureus.

\section{Conflict of Interests}

The authors declare that there is no conflict of interests regarding the publication of this paper.

\section{Acknowledgments}

This work was supported in part by Warner/Fermaturo and ATSU Board of Trustees Research Funds and Grant 1R15AI090680-01 from the National Institutes of Health to Vineet K. Singh and a grant from KCOM Biomedical Sciences Graduate Program to Kyle R. Baum.

\section{References}

[1] M. J. Kuehnert, D. Kruszon-Moran, H. A. Hill et al., "Prevalence of Staphylococcus aureus nasal colonization in the United States, 2001-2002," The Journal of Infectious Diseases, vol. 193, no. 2, pp. 172-179, 2006.

[2] G. L. Archer, "Staphylococcus aureus: a well-armed pathogen," Clinical Infectious Diseases, vol. 26, no. 5, pp. 1179-1181, 1998.

[3] F. D. Lowy, "Staphylococcus aureus infections," The New England Journal of Medicine, vol. 339, no. 8, pp. 520-532, 1998.

[4] E. A. Morell and D. M. Balkin, "Methicillin-resistant Staphylococcus aureus: a pervasive pathogen highlights the need for new antimicrobial development," Yale Journal of Biology and Medicine, vol. 83, no. 4, pp. 223-233, 2010.

[5] V. K. Singh, R. K. Jayaswal, and B. J. Wilkinson, "Cell wall-active antibiotic induced proteins of Staphylococcus aureus identified using a proteomic approach," FEMS Microbiology Letters, vol. 199, no. 1, pp. 79-84, 2001.

[6] V. K. Singh, J. Moskovitz, B. J. Wilkinson, and R. K. Jayaswal, "Molecular characterization of a chromosomal locus in Staphylococcus aureus that contributes to oxidative defence and is highly induced by the cell-wall-active antibiotic oxacillin," Microbiology, vol. 147, part 11, pp. 3037-3045, 2001.

[7] E. Cabiscol, J. Tamarit, and J. Ros, "Oxidative stress in bacteria and protein damage by reactive oxygen species," International Microbiology, vol. 3, no. 1, pp. 3-8, 2000.

[8] J. Moskovitz, V. K. Singh, J. Requena, B. J. Wilkinson, R. K. Jayaswal, and E. R. Stadtman, "Purification and characterization of methionine sulfoxide reductases from mouse and Staphylococcus aureus and their substrate stereospecificity," Biochemical and Biophysical Research Communications, vol. 290, no. 1, pp. 62-65, 2002.

[9] V. K. Singh and J. Moskovitz, "Multiple methionine sulfoxide reductase genes in Staphylococcus aureus: expression of activity and roles in tolerance of oxidative stress," Microbiology, vol. 149, no. 10, pp. 2739-2747, 2003.

[10] V. K. Singh, M. Vaish, T. R. Johansson et al., "Significance of four methionine sulfoxide reductases in Staphylococcus aureus," PLoS ONE, vol. 10, no. 2, Article ID e0117594, 2015.

[11] M. J. Horsburgh, J. L. Aish, I. J. White, L. Shaw, J. K. Lithgow, and S. J. Foster, " $\delta$ ${ }^{B}$ modulates virulence determinant expression and stress resistance: characterization of a functional rsbU strain derived from Staphylococcus aureus 8325-4," Journal of Bacteriology, vol. 184, no. 19, pp. 5457-5467, 2002.

[12] P. F. Chan, S. J. Foster, E. Ingham, and M. O. Clements, "The Staphylococcus aureus alternative sigma factor sigmaB controls the environmental stress response but not starvation survival or pathogenicity in a mouse abscess model," Journal of Bacteriology, vol. 180, no. 23, pp. 6082-6089, 1998.

[13] K. Singh and V. K. Singh, "Expression of four methionine sulfoxide reductases in Staphylococcus aureus," International Journal of Microbiology, vol. 2012, Article ID 719594, 8 pages, 2012.

[14] V. K. Singh, M. Syring, A. Singh, K. Singhal, A. Dalecki, and T. Johansson, "An insight into the significance of the DnaK heat shock system in Staphylococcus aureus," International Journal of Medical Microbiology, vol. 302, no. 6, pp. 242-252, 2012.

[15] H. Eleaume and S. Jabbouri, "Comparison of two standardisation methods in real-time quantitative RT-PCR to follow Staphylococcus aureus genes expression during in vitro growth," Journal of Microbiological Methods, vol. 59, no. 3, pp. 363-370, 2004.

[16] C. Goerke, S. Campana, M. G. Bayer, G. Döring, K. Botzenhart, and C. Wolz, "Direct quantitative transcript analysis of the agr regulon of Staphylococcus aureus during human infection in comparison to the expression profile in vitro," Infection and Immunity, vol. 68, no. 3, pp. 1304-1311, 2000.

[17] K. J. Livak and T. D. Schmittgen, "Analysis of relative gene expression data using real-time quantitative PCR and the 2(Delta Delta C(T)) method," Methods, vol. 25, no. 4, pp. 402-408, 2001.

[18] R. Pechous, N. Ledala, B. J. Wilkinson, and R. K. Jayaswal, "Regulation of the expression of cell wall stress stimulon member gene msrAl in methicillin-susceptible or -resistant Staphylococcus aureus," Antimicrobial Agents and Chemotherapy, vol. 48, no. 8, pp. 3057-3063, 2004.

[19] L. A. Denkel, S. A. Horst, S. F. Rouf et al., "Methionine sulfoxide reductases are essential for virulence of Salmonella typhimurium," PLoS ONE, vol. 6, no. 11, Article ID e26974, 2011.

[20] Y. Y. Pang, J. Schwartz, S. Bloomberg, J. M. Boyd, A. R. Horswill, and W. M. Nauseef, "Methionine sulfoxide reductases protect against oxidative stress in Staphylococcus aureus encountering exogenous oxidants and human neutrophils," Journal of Innate Immunity, vol. 6, no. 3, pp. 353-364, 2014.

[21] M. Saleh, S. G. Bartual, M. R. Abdullah et al., "Molecular architecture of Streptococcus pneumoniae surface thioredoxin-fold lipoproteins crucial for extracellular oxidative stress resistance and maintenance of virulence," EMBO Molecular Medicine, vol. 5, no. 12, pp. 1852-1870, 2013.

[22] S. J. Sasindran, S. Saikolappan, and S. Dhandayuthapani, "Methionine sulfoxide reductases and virulence of bacterial pathogens," Future Microbiology, vol. 2, no. 6, pp. 619-630, 2007.

[23] C. Zhao, A. Hartke, M. La Sorda et al., "Role of methionine sulfoxide reductases A and B of Enterococcus faecalis in oxidative stress and virulence," Infection and Immunity, vol. 78, no. 9, pp. 3889-3897, 2010. 
[24] S. Dhandayuthapani, M. W. Blaylock, C. M. Bebear, W. G. Rasmussen, and J. B. Baseman, "Peptide methionine sulfoxide reductase (MsrA) is a virulence determinant in Mycoplasma genitalium," Journal of Bacteriology, vol. 183, no. 19, pp. 56455650, 2001.

[25] T. M. Wizemann, J. Moskovitz, B. J. Pearce et al., "Peptide methionine sulfoxide reductase contributes to the maintenance of adhesins in three major pathogens," Proceedings of the National Academy of Sciences of the United States of America, vol. 93, no. 15, pp. 7985-7990, 1996.

[26] S. Mizobuchi, J. Minami, F. Jin, O. Matsushita, and A. Okabe, "Comparison of the virulence of methicillin-resistant and methicillin-sensitive Staphylococcus aureus," Microbiology and Immunology, vol. 38, no. 8, pp. 599-605, 1994.

[27] N. M. van Sorge, F. C. Beasley, I. Gusarov et al., "Methicillinresistant Staphylococcus aureus bacterial nitric-oxide synthase affects antibiotic sensitivity and skin abscess development," The Journal of Biological Chemistry, vol. 288, no. 9, pp. 6417-6426, 2013.

[28] M. Vaish and V. K. Singh, "Antioxidant functions of nitric oxide synthase in a methicillin sensitive Staphylococcus aureus," International Journal of Microbiology, vol. 2013, Article ID 312146, 6 pages, 2013.

[29] M. Pantrangi, V. K. Singh, and S. K. Shukla, "Regulation of Staphylococcal superantigen-like gene, ssl8, expression in Staphylococcus aureus strain, RN6390," Clinical Medicine \& Research, vol. 13, no. 1, pp. 7-11, 2015.

[30] M. Pantrangi, V. K. Singh, C. Wolz, and S. K. Shukla, "Staphylococcal superantigen-like genes, $s s l 5$ and $s s l 8$, are positively regulated by Sae and negatively by Agr in the Newman strain," FEMS Microbiology Letters, vol. 308, no. 2, pp. 175-184, 2010.

[31] S. J. Cordwell, M. R. Larsen, R. T. Cole, and B. J. Walsh, "Comparative proteomics of Staphylococcus aureus and the response of methicillin-resistant and methicillin-sensitive strains to Triton X-100," Microbiology, vol. 148, no. 9, pp. 2765-2781, 2002.

[32] J. Bos, Y. Duverger, B. Thouvenot et al., "The sRNA RyhB regulates the synthesis of the Escherichia coli methionine sulfoxide reductase MsrB but not MsrA," PLoS ONE, vol. 8, no. 5, Article ID e63647, 2013.

[33] Y.-T. Hsu and T.-M. Lee, "Nitric oxide up-regulates the expression of methionine sulfoxide reductase genes in the intertidal macroalga Ulva fasciata for high light acclimation," Plant and Cell Physiology, vol. 53, no. 2, pp. 445-456, 2012.

[34] I. Hanbauer, E. S. Boja, and J. Moskovitz, "A homologue of elongation factor 1 gamma regulates methionine sulfoxide reductase a gene expression in Saccharomyces cerevisiae," Proceedings of the National Academy of Sciences of the United States of America, vol. 100, no. 14, pp. 8199-8204, 2003.

[35] C. You, A. Sekowska, O. Francetic, I. Martin-Verstraete, Y. Wang, and A. Danchin, "Spx mediates oxidative stress regulation of the methionine sulfoxide reductases operon in Bacillus subtilis," BMC Microbiology, vol. 8, article 128, 2008.

[36] A. Renzoni, D. O. Andrey, A. Jousselin et al., "Whole genome sequencing and complete genetic analysis reveals novel pathways to glycopeptide resistance in Staphylococcus aureus," PLoS ONE, vol. 6, no. 6, Article ID e21577, 2011.

[37] R. F. Pfeltz, V. K. Singh, J. L. Schmidt et al., "Characterization of passage-selected vancomycin-resistant Staphylococcus aureus strains of diverse parental backgrounds," Antimicrobial Agents and Chemotherapy, vol. 44, no. 2, pp. 294-303, 2000.

[38] V. K. Singh, J. L. Schmidt, R. K. Jayaswal, and B. J. Wilkinson, "Impact of sigB mutation on Staphylococcus aureus oxacillin and vancomycin resistance varies with parental background and method of assessment," International Journal of Antimicrobial Agents, vol. 21, no. 3, pp. 256-261, 2003. 

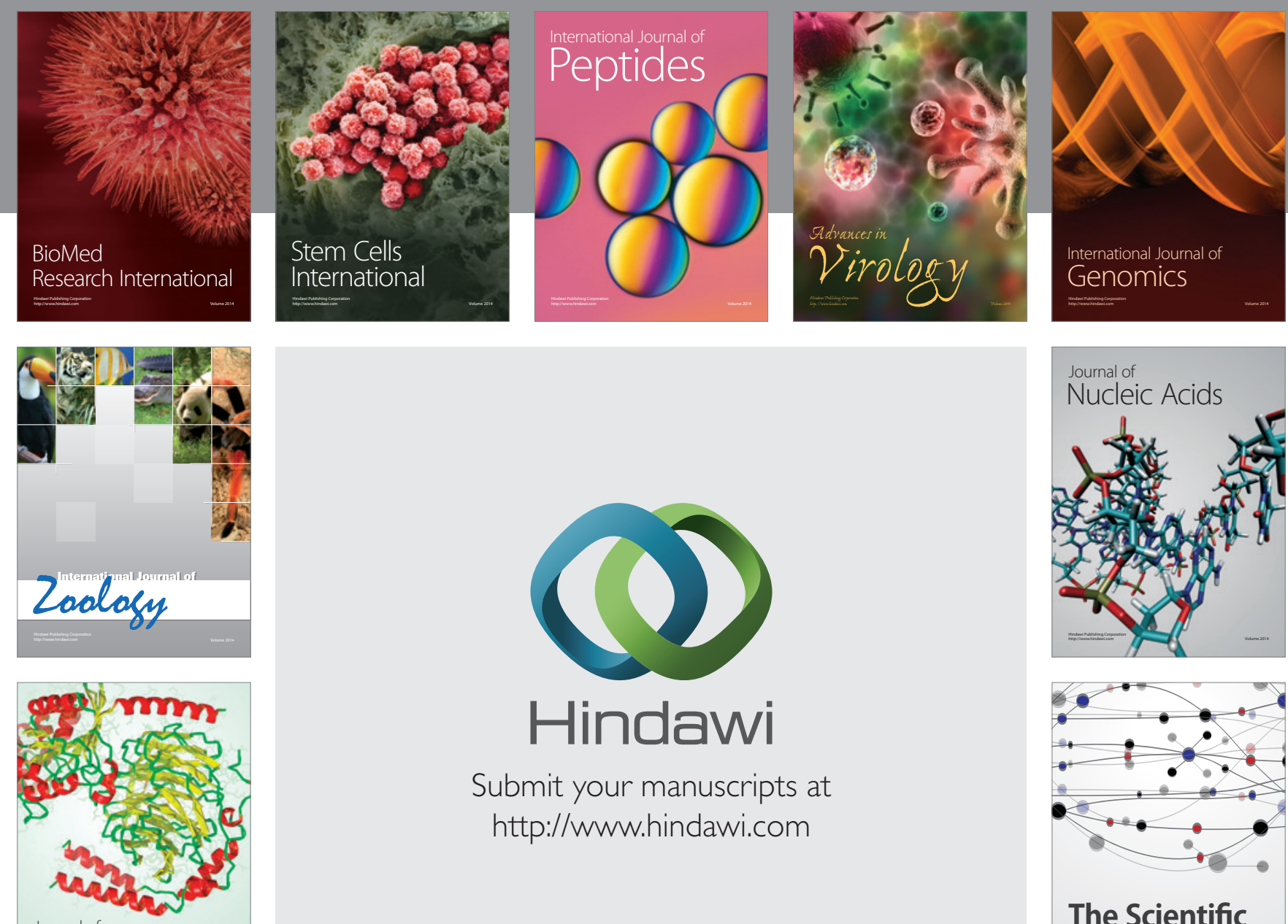

Submit your manuscripts at

http://www.hindawi.com

Journal of
Signal Transduction
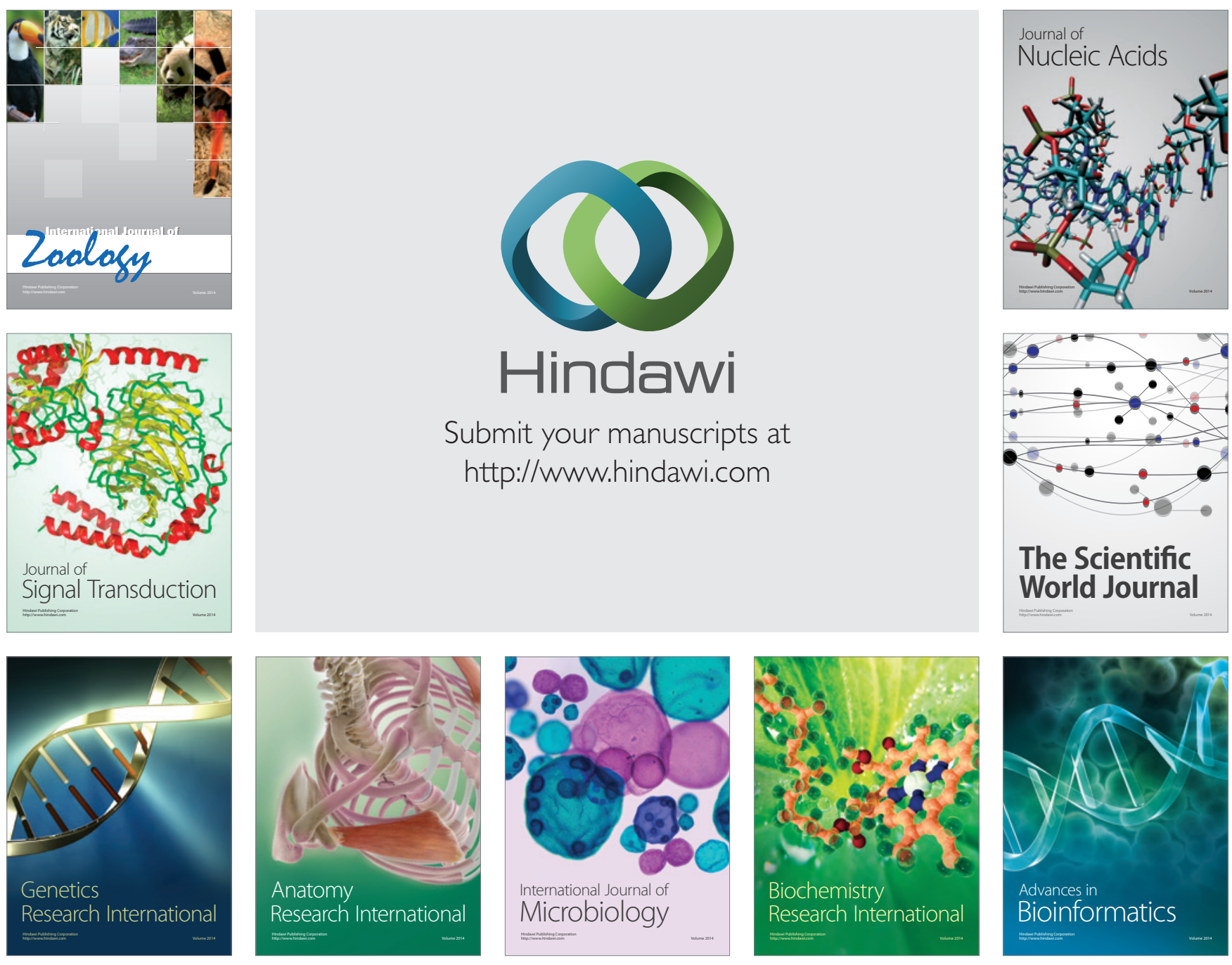

The Scientific World Journal
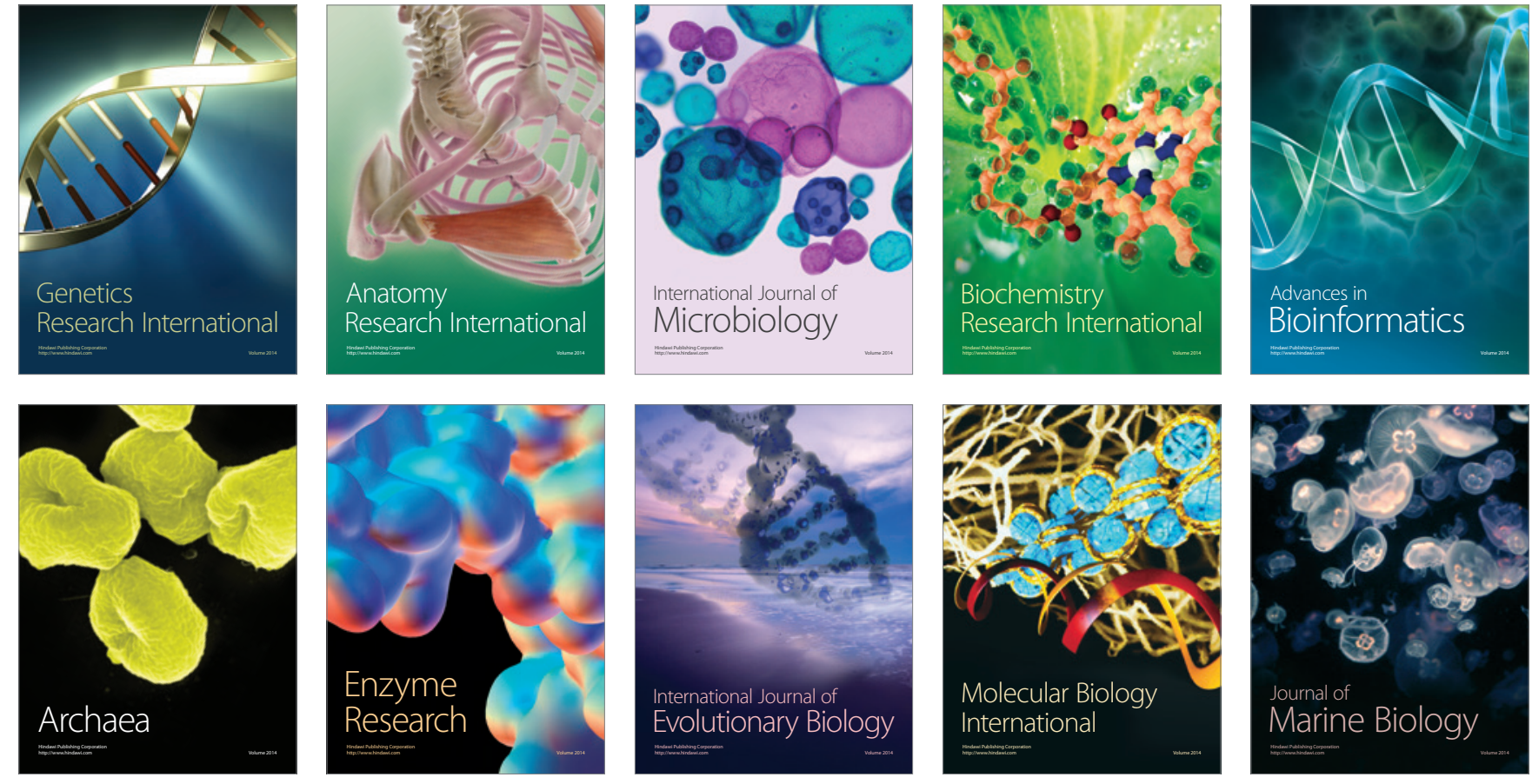